\title{
Pengaruh Food Quality, Price, Service Quality dan Perceived Value terhadap Customer Loyality pada Restoran Aneka Rasa Jambi dengan Customer Satisfaction sebagai Variabel Intervening
}

\author{
Novita Sari, Ade Perdana Siregar \\ Jurusan Manajemen Fakultas Ekonomi dan Bisnis Universitas Jambi, \\ Correspondence email: arkaanraja@yahoo.co.id
}

\begin{abstract}
Indonesia is the fourth most populous country in the world, after China, India and the United States, with a population of 2018 of around 267 million. The increase in the average population will be a major contributor to the growth of the food and beverage industry. Today's mobility of people is getting higher so it consumes food outside the home. Restaurant products are determined by five factors, namely food and beverage factors, service factors, hygiene and hygiene factors, price factors and atmospheric factors, whereas based on the activities and food or drinks served, restaurants are classified into twenty types ranging from A'la carte restaurant to main dining room. The objectives of this study are: (1) to analyze the effect of food quality, price, service quality and partial perceived value on customer satisfaction; (2) partially analyze the influence of food quality, price, service quality and perceived value on customer loyalty; (3) analyze customer satisfaction mediation due to the influence of food quality, price, service quality and perceived value on customer loyalty. The sample was determined using the Slovin formula of 100 respondents. Survey method with descriptive and quantitative analysis. The analytical tool used in this study is the smartpls application version 3.0. The results of the study note that food quality, price, service quality and perceived value affect customer satisfaction, food quality, price, service quality and perceived value affect customer loyalty and customer satisfaction can mediate the relationship between food quality, price, service quality and perceived value towards customer loyalty.
\end{abstract}

Keywords : Customer Satisfaction, Customer Loyality

\section{PENDAHULUAN}

Indonesia adalah negara dengan jumlah penduduk terbesar nomor empat di dunia, setelah Cina, India dan Amerika Serikat, dengan jumlah penduduk di tahun 2018 adalah sekitar 267 juta jiwa. Jika dibandingkan dengan tahun 2016 maupun 2017, terjadi peningkatan jumlah penduduk yang cukup signifikan, dimana jumlah penduduk di tahun 2016 adalah sekitar 259 juta jiwa naik menjadi 262 juta jiwa di tahun 2017 (Kompas.com, 2019). Peningkatan rata-rata jumlah penduduk ini akan menjadi penyumbang utama pertumbuhan industri makanan dan minuman. Menurut Abraham Maslow ada lima tingkatan kebutuhan manusia yaitu kebutuhan fisiologis, rasa aman, rasa memiliki, harga diri dan akumulasi diri. Kebutuhan mendasar yang harus dipenuhi oleh manusia untuk mempertahankan hidupnya adalah kebutuhan fisiologis, yaitu kebutuhan akan makanan, minuman, tempat tinggal, bernafas dan kebutuhan seksual (Dalam Mangkunegara, 2005). Untuk itu, kebutuhan dasar ini selalu menjadi salah satu sektor potensial untuk terus berkembang.

Mobilitas masyarakakat dewasa ini juga semakin tinggi, dalam rangka memperoleh pendapatan untuk membiayai kebutuhan yang semakin mahal ataupun semakin bervariasi. Tidak lagi hanya suami yang mencari nafkah tapi istri juga bekerja untuk membantu perekonomian keluarga. Karena itulah sebagian besar mereka tidak memiliki waktu untuk memasak lalu mengkonsumsi makanan di luar rumah, apakah itu di warung ataupun restoran. Dalam sebuah penelitian yang dilakukan sepanjang April 2017 sampai Maret 2018 oleh Roy Morgan, mencatat bahwa sebanyak 55 juta penduduk di Indonesia mulai dari usia 14 tahun keatas gemar makan di restoran, apakah itu restoran khas Indonesia maupun lainnya (Merdeka.com, 2019). Besarnya potensi sektor industri makanan dan minuman ini, menjadikannya andalan pada program Making Indonesia 4.0. Restoran atau rumah makan adalah usaha penyediaan jasa makanan dan minuman yang dilengkapi dengan peralatan mulai dari proses pembuatan, penyimpanan dan penyajian di suatu tempat tetap yang tidak berpindah-pindah dengan tujuan memperoleh keuntungan (Permen Pariwisata dan Ekonomi Kreatif No.11 Tahun 2014). Menurut Cousin dkk (2002) produk restoran ditentukan oleh lima faktor yaitu Faktor makanan dan minuman, faktor pelayanan, faktor kebersihan dan higienitas, faktor harga dan faktor atmosfir/suasana. Sedangkan berdasarkan kegiatan dan makanan atau minuman yang disajikan, restoran diklasifikasi menjadi dua puluh jenis (Atmodjo, 2005) mulai dari A'la carte restaurant sampai dengan main dining room. 
Berdasarkan data yang diperoleh dari BPS Jambi, jumlah restoran yang tercatat di kota Jambi saat ini adalah sebanyak 91 buah. Salah satu restoran yang ada di kota Jambi adalah restoran Aneka Rasa. Restoran ini berlokasi di daerah kebun jeruk yang menyajikan makanan Indonesia, Cina dan Asia. Restoran ini telah berdiri sejak tahun 1984 dan tetap menjadi salah satu tujuan utama wisata kuliner di Kota Jambi. Restoran ini juga masuk dalam sepuluh besar restoran yang wajib dikunjungi berdasarkan tripadvisor.co.id dan memperoleh penilaian 4,5 bintang dari para pelanggannya. Restoran Aneka Rasa memiliki kekhasan tersendiri yang dijaga seiring waktu berjalan. Mulai dari bentuk ruang makannya, pelayanan, sampai dengan kualitas makanan dan minumannya yang terjaga standarnya. Variasi menu makanan dan minuman mengalami penambahan, disesuaikan dengan keinginan pelanggan. Walaupun banyak bermunculan restoran ataupun rumah makan lainnya, restoran Aneka Rasa ini berhasil bertahan dan tetap memiliki tempat dihati para pelangannya. Besarnya biaya yang diperlukan untuk memenuhi kebutuhan saat ini membuat tingkat mobilitas masyarakat di Indonesia semakin tinggi. Tidak lagi hanya suami yang mencari nafkah tapi istri juga bekerja untuk membantu perekonomian keluarga. Karenanya semakin banyak yang tidak memiliki waktu untuk memasak sehingga mengkonsumsi makanan di luar rumah, apakah itu di warung ataupun restoran. Restoran atau rumah makan adalah usaha penyediaan jasa makanan dan minuman dilengkapi dengan peralatan dan perlengkapan untuk proses pembuatan, penyimpanan dan penyajian di suatu tempat tetap yang tidak berpindah-pindah dengan tujuan memperoleh keuntungan dan/atau laba (Permen Pariwisata dan Ekonomi Kreatif No.11 Tahun 2014).

Fenomena yang tidak jauh berbeda terjadi di kota Jambi. Jumlah rumah makan ataupun restoran semakin banyak, dengan berbagai spesifikasi tersendiri. Ada yang mampu bertahan namun tidak sedikit juga yang tidak beroperasional lagi. Salah satu restoran yang masih bertahan di kota Jambi adalah Aneka Rasa. Untuk tetap bertahan dan berkembang di masa depan, maka food quality, price, service quality dan perceived value perlu mendapat perhatian penting. Food Quality merupakan hal penting yang harus diperhatikan oleh restaurant dikarenakan makanan merupakan produk utama yang ditawarkan oleh restaurant kepada konsumen mereka sehingga restaurant harus menjaga harapan konsumen mengenai kualitas dari produk yang ditawarkan oleh restaurant kepada Konsumen (Walter et al., 2010; Jang and Mankung 2009).

Dalam penelitian ini, produk utama yang dibahas adalah makanan. Menurut Knight dan Kotschevar (2000) kualitas makanan merupakan suatu tingkatan dalam konsistensi kualitas menu yang dicapai dengan penetapan suatu standar produk dan kemudian mengecek poin-poin yang harus dikontrol untuk melihat kualitas yang ingin dicapai. Harga merupakan faktor selanjutnya yang harus dianalisis dalam penelitian ini. Zethaml dan Bitner (2006) menyebutkan bahwa jasa sangat mempengaruhi persepsi tentang kualitas, kepuasan dan nilai (value), karena jasa tak berwujud dan sulit dinilai sebelum pembelian, maka harga biasanya dianggap sebagai inikator yang bisa mempengaruhi persepsi dan harapan akan kualitas. Jika harga sangat tinggi, maka pelanggan biasanya mengharapkan kualitas tinggi dan persepsi aktualnya akan dipengaruhi oleh harapan ini. Sebaliknya, jika harga terlalu rendah, maka pelanggan mungkin meragukan kemampuan organisasi dalam hal kualitas jasa. Service Quality adalah konsep sering diperdebatkan dalam penelitian literatur karena kesulitan dalam mendefinisikan dan mengukurnya karena tidak ada kosensus keseluruhan yang muncul (Wisniewski, 2005). Service Quality yaitu penilaian kualitas layanan sejauh mana layanan yang diberikan memenuhi kebutuhan atau harapan dari pelanggan. Hasil penilaian ini dijadikan sebagai perbandingan antara ekspektasi konsumen dengan kenyatan pelayanan yang diberikan. Jika ekspektasi lebih besar daripada yang didapatkan maka konsumen akan merasa kecewa (Parasuraman et al., 1985; Lewis and Mitchell, 1990).

Perceived Value adalah penilaian konsumen secara keseluruhan terhadap manfaat produk dengan didasarkan pada apa yang mereka terima dan apa yang mereka berikan. Penilaian ini dalam pandangan dari konsumen apakah benefit yang didapatkan sesuai dengan hal yang dikorbankannya (Kotler, 2003). Dalam Ariningsih (2010) riset yang dilakukan dua pakar pemasaran dari University of Western Australia,S weeney dan Soutar (2001) berusaha mengembangkan 19 item ukuran customer perceived value. Skala yang dinamakan PERVAL (Perceived Value) tersebut dimaksudkan untuk menilai persepsi pelanggan terhadap nilai suatu produk Pelanggan tahan lama pada level merek. Skala ini dikembangkan berdasarkan konteks situasi pembelian ritel untuk menentukan nilai-nilai konsumsi yang mengarah pada sikap dan perilaku 
pembelian. Keempat variable diatas akan menentukan sikap konsumen tentang penilaian mereka terhadap restoran Aneka Rasa. Apakah mereka merasa puas atau sebaliknya. Menurut Kotler dan Armstrong (2007) Kepuasan konsumen adalah perasaan senang atau kecewa seseorang yang muncul setelah membandingkan kinerja produk yang dipikirkan terhadap kinerja yang diharapkan. Bila kinerja produk lebih rendah ketimbang harapan pelanggan, maka pembelinya merasa puas atau amat gembira.

Ketika pelanggan merasa keinginan dan kebutuhannya terpenuhi sesuai dengan harapannya maka akan tercipta loyalitas. Menurut Kotler dan Keller (2006 dalam Rudika, 2014) Loyalitas adalah sebuah konsep yang menekankan pada tuntutan pembelian, proporsi pembelian, atau probabilitas pembelian. Menuru Basu Swastha, 1997 (dalam Rudika, 2014) Loyalitas adalah kebiasaan perilaku pengulangan pembelian, keterkaitan dan keterlibatan yang tinggi pada pilihannya, dan bercirikan dengan pencarian informasi eksternal dan evaluasi alternatif. Pelanggan yang merasa nyaman dengan nilai dan pelayanan didapat, maka mereka akan berpotensi untuk menjadi loyal, karna itulah tujuan akhir perusahaan yang berhasil yaitu menjalin hubungan dengan pelanggannya adalah untuk membentuk loyalitas yang kuat. Tujuan dari penelitian ini adalah: (1) menganalisis pengaruh food quality, price, service quality dan perceived value secara parsial terhadap customer satisfaction; (2) menganalisis pengaruh food quality, price, service quality dan perceived value secara parsial terhadap customer loyality; (3) menganalisis mediasi customer satisfaction akibat pengaruh food quality, price, service quality dan perceived value terhadap customer loyality.

\section{METODE}

Objek dalam penelitian ini adalah para pelanggan Restoran Aneka Rasa Jambi. Restoran aneka rasa beralamat di Jalan Mpu Gandring No. 75 Kebun Jeruk Kelurahan Solok Sipin Kecamatan Telanaipura Kota Jambi. Jenis data yang digunakan adalah (1) Data primer yaitu Data diperoleh melalui kuesioner tertutup yang meliputi karakteristik responden dan persepsi responden variable yang diteliti. Pengumpulan data primer menggunakan metode Non Probability Sampling dan Jenis Purposive Sampling, dimana sampel dipilih berdasarkan orang yang mudah ditemui dan mau bekerja sama, dengan syarat adalah pelanggan Restoran Aneka Rasa dengan minimal kunjungan dua kali. (2) Data sekunder yaitu data yang diperoleh dari tinjauan kepustakaan melalui literatur, jurnal-jurnal dan situs internet yang dapat memberikan informasi sesuai dengan masalah penelitian. Populasi pada penelitian ini adalah para pelanggan Restoran Aneka Rasa Jambi sepanjang tahun 2018 yaitu sebanyak 25.000 pengunjung. Sampel ditentukan dengan menggunakan rumus slovin yaitu sebanyak 100 orang responden.

Variabel yang digunakan yaitu dapat dilihat pada tabel berikut ini :

Tabel 1.

Operasionalisasi Variabel

\begin{tabular}{|c|c|c|c|}
\hline Variabel & Definisi & Indikator & Skala \\
\hline $\begin{array}{l}\text { Food Quality } \\
\left(\mathrm{X}_{1}\right)\end{array}$ & $\begin{array}{l}\text { Menurut Knight dan Kotschevar (2000) kualitas } \\
\text { makanan merupakan suatu tingkatan dalam } \\
\text { konsistensi kualitas menu yang dicapai dengan } \\
\text { penetapan suatu standar produk dan kemudian } \\
\text { mengecek poin-poin yang harus dikontrol untuk } \\
\text { melihat kualitas yang ingin dicapai }\end{array}$ & $\begin{array}{ll} & \text { Kualitas rasa } \\
\text { - } & \text { Kuantitas atau porsi } \\
\text { - } & \text { Variasi menu dan variasi jenis } \\
& \text { masakan yang ditawarkan } \\
\text { - } & \text { Cita rasa yang khas } \\
\text { - } & \text { Higienitas } \\
\text { - } & \text { Inovasi } \\
\end{array}$ & Ordinal \\
\hline $\begin{array}{l}\text { Price } \\
\left(\mathrm{X}_{2}\right)\end{array}$ & $\begin{array}{l}\text { Harga merupakan sesuatu komponenn yang } \\
\text { diberikan sebagai ganti atas komponen yang } \\
\text { didapatkan (Zeithaml dan Bitner,2006) }\end{array}$ & $\begin{array}{l}\text { - } \quad \text { Value is Low Price } \\
\text { - } \quad \text { Value is whatever I want in a } \\
\text { product or service } \\
\text { - } \quad \text { Value is the quality I get for the } \\
\text { price I pay } \\
\text { - Value is what I get for what I give }\end{array}$ & Ordinal \\
\hline Service Quality $\left(\mathrm{X}_{3}\right)$ & $\begin{array}{l}\text { Penilaian kualitas layanan sejauh mana layanan yang } \\
\text { diberikan memenuhi kebutuhan atau harapan dari } \\
\text { pelanggan Hasil penilaian ini dijadikan sebagai } \\
\text { perbandingan antara ekspektasi konsumen dengan } \\
\text { kenyatan pelayanan yang diberikan. (Parasuraman et } \\
\text { al., 1985; Lewis and Mitchell, 1990). }\end{array}$ & $\begin{array}{ll}- & \text { Tangible } \\
- & \text { Reliability } \\
- & \text { Responsiveness } \\
- & \text { Assurance } \\
\text { Emphaty }\end{array}$ & Ordinal \\
\hline
\end{tabular}


Novita Sari dan Ade Perdana Siregar, Pengaruh Food Quality, Price, Service Quality dan Perceived Value terhadap Customer Loyality pada Restoran Aneka Rasa Jambi dengan Customer Satisfaction sebagai Variabel Intervening

\begin{tabular}{|c|c|c|c|}
\hline $\begin{array}{l}\text { Perceived } \\
\left(\mathrm{X}_{4}\right)\end{array}$ & $\begin{array}{l}\text { Penilaian konsumen secara keseluruhan terhadap } \\
\text { manfaat produk dengan didasarkan pada apa yang } \\
\text { mereka terima dan apa yang mereka berikan. } \\
\text { (Kotler, 2003) }\end{array}$ & $\begin{array}{ll}- & \text { Emotional Value } \\
\text { - } & \text { Social Value } \\
\text { - } & \text { Quality/Performance Value } \\
\text { - } & \text { Price/Value of Money } \\
\end{array}$ & Ordinal \\
\hline $\begin{array}{l}\text { Customer } \\
\text { Satisfaction } \\
(\mathrm{Z})\end{array}$ & $\begin{array}{l}\text { Perasaan senang atau kecewa seseorang yang } \\
\text { muncul setelah membandingkan kinerja produk } \\
\text { yang dipikirkan terhadap kinerja yang diharapkan } \\
\text { Kotler dan Armstrong (2007) }\end{array}$ & $\begin{array}{ll}- & \text { Attributes related to product } \\
\text { - } & \text { Attributes related to service } \\
\text { - } & \text { Attributes related to purchase }\end{array}$ & \\
\hline $\begin{array}{l}\text { Customer Loyality } \\
\text { (Y) }\end{array}$ & $\begin{array}{l}\text { Loyalitas Pelanggan adalah sebuah konsep yang } \\
\text { menekankan pada tuntutan pembelian, proporsi } \\
\text { pembelian, atau probabilitas pembelian (Kotler dan } \\
\text { Keller, } 2006 \text { dalam Rudika, 2014) }\end{array}$ & $\begin{array}{ll}\text { - } & \text { Kesetiaan terhadap pembelian } \\
\text { produk } \\
\text { - } \quad \text { Ketahanan terhadap pengaruh } \\
\text { yang negatif mengenai produk } \\
\text { - } \\
\text { Mereferensikan secara total } \\
\text { eksistensi perusahaan }\end{array}$ & \\
\hline
\end{tabular}

Data dikumpulkan melalui instrumen penelitian berupa kuesioner sehingga diperlukan uji validitas dan reliabilitas agar kuesioner layak digunakan. Alat analisis yang digunakan adalah SEM dengan menggunakan software PLS (partial least square).

\section{HASIL}



Gambar 1

Model Hasil Pengukuran

Pada gambar diatas terlihat hubungan antar variabel dimana variabel Food Quality, Price, Service Quality dan Perceived Value menunjukan pengaruh terhadap variabel Customer Satisfaction dan variabel Food Quality, Price, Service Quality dan Perceived Value menunjukan pengaruh terhadap variabel Customer loyality serta variabel Customer Satisfaction sebagai mediasi pengaruh variabel Food Quality, Price, Service Quality dan Perceived Value menunjukan pengaruh terhadap variabel Customer loyality. Pengukuran pengujian reabilitas dengan menganalisis melalui Cronbach's Alpha, Composite Reliability dan Average Variance Extracted (AVE). Skor minimum pada setiap variabel dapat dinyatakan reabilitas yaitu jika Cronbach's Alpha dan Composite Reliability lebih dari 0,7 dan dinyatakan validitas jika Average Variance Extracted (AVE) lebih dari 0,5. Hasil perhitungan dapat dilihat sebagai berikut : 
Novita Sari dan Ade Perdana Siregar, Pengaruh Food Quality, Price, Service Quality dan Perceived Value terhadap Customer Loyality pada Restoran Aneka Rasa Jambi dengan Customer Satisfaction sebagai Variabel Intervening

Tabel 2.

Construct Reliability and Validity

\begin{tabular}{lllll}
\hline & Cronbach's Alpha & rho_A & $\begin{array}{l}\text { Composite } \\
\text { Reliability }\end{array}$ & $\begin{array}{l}\text { Average } \\
\text { Extracted (AVE) }\end{array}$ \\
\hline Customer Loyality & 0,781 & 0,784 & 0,873 & 0,697 \\
Customer Satisfaction & 0,908 & 0,908 & 0,929 & 0,686 \\
Food Quality & 0,901 & 0,902 & 0,924 & 0,668 \\
Perceived Value & 0,832 & 0,832 & 0,888 & 0,665 \\
Price & 0,855 & 0,859 & 0,903 & 0,699 \\
Service Quality & 0,953 & 0,954 & 0,959 & 0,682 \\
\hline
\end{tabular}

Sumber: data olahan

Analisis cronbach's alpha pada tabel di atas, hasil menunjukan bahwa skor lebih dari 0,7 dimana variabel customer loyality sebesar 0,781, customer satisfaction sebesar 0,908, food quality sebesar 0,901, perceived value sebesar 0,832 , price sebesar 0,855 dan service quality sebesar 0,953. Hasil tersebut menunjukan bahwa keakuratan dan kehandalan semua variabel dalam penelitian ini. Composite reliability dengan skor di atas 0,7 maka dapat dinyatakan memenuhi reabilitas. Berdasarkan table di atas, maka terlihat bahwa setiap variabel pada penelitian ini skor untuk composite reliability diatas 0,7 dimana variabel customer loyality sebesar 0,873, customer satisfaction sebesar 0,929, food quality sebesar 0,924, perceived value sebesar 0,888 , price sebesar 0,903 dan service quality sebesar 0,959. Hasil tersebut menunjukan bahwa variabel secara keseluruhan dinyatakan realibel. Pengukuran validitas melalui Average Variance Extracted $(A V E)$ dimana skor diatas 0,5 maka dinyatakan memenuhi validitas. Berdasarkan tabel diatas terlihat bahwa secara keseluruhan variabel skor Average Variance Extracted (AVE) diatas 0,5, dimana customer loyality sebesar 0,697, customer satisfaction sebesar 0,686, food quality sebesar 0,668, perceived value sebesar 0,665, price sebesar 0,699 dan service quality sebesar 0,682. Hasil tersebut menunjukan bahwa variabel secara keseluruhan dinyatakan memenuhi validitas.

Berdasarkan hasil penelitian yang dilakukan dan hasil kuesioner yang dibagikan kepada 100 responden maka analisis lebih lanjut mengenai hasil penelitian ini diinterpretasikan dengan pembahasan berikut. Menurut Kotler dan Keller, 2006, loyalitas pelanggan adalah sebuah konsep yang menekankan pada tuntutan pembelian, proporsi pembelian, atau probabilitas pembelian. Pelayanan yang baik akan menumbuhkan sikap loyal konsumen, dimana hal tersebut dapat terlihat setia kosumen dalam mengkonsumsi produk, ketahanan terhadap pengaruh negatif pada produk dan mereferensikan produk kepada orang lain. Sikap tersebut terbentuk dengan adanya rasa puas setelah mendapatkan pelayanan atau konsumsi pada suatu produk. Menurut Kotler dan Armstrong (2007), customer satisfaction merupakan perasaan senang atau kecewa seseorang yang muncul setelah membandingkan kinerja produk yang dipikirkan terhadap kinerja yang diharapkan. Pada penelitian ini, restoran aneka rasa merupakan objek dalam penelitian. Pengukuran pengaruh Food Quality, Price, Service Quality dan Perceived Value terhadap Customer Satisfaction dan pengaruh Food Quality, Price, Service Quality dan Perceived Value secara parsial terhadap Customer Loyality. Hasil analisis data melalui Partial Least Square (PLS) menunjukan terdapat pengaruh yang signifikan terhadap hal tersebut.

Menurut Knight dan Kotschevar (2000), kualitas makanan merupakan suatu tingkatan dalam konsistensi kualitas menu yang dicapai dengan penetapan suatu standar produk dan kemudian mengecek poin-poin yang harus dikontrol untuk melihat kualitas yang ingin dicapai. Menurut pengamatan selama penelitian ini, restoran aneka rasa sangat menjaga kualitas makanan dengan rasa yang menciptakan kepuasan bagi pelanggan, sehingga seiring dengan hasil penelitian ini terdapat pengaruh kualitas makanan terhadap kepuasan konsumen dan loyalitas konsumen. Menurut Zeithaml dan Bitner (2006), harga merupakan sesuatu komponenn yang diberikan sebagai ganti atas komponen yang didapatkan. Pada penelitian ini harga memberikan pengaruh signifikan terhadap kepuasan dan loyalitas konsumen. Penelitian ini sesuai dengan yang dikatakan oleh Zeithaml dan Bitner harga memberikan pengaruh terhadap kepuasan dan loyalitas, dimana setiap individu dapat berkorban dengan mengaharapkan sebuah kepuasan Menurut Lewis and Mitchell (1990), penilaian kualitas layanan sejauh mana layanan yang diberikan memenuhi kebutuhan atau harapan dari pelanggan. Pada penelitian ini sejalan dengan penelitian Lewis and Mitchell (1990) dengan hasil penilaian ini dijadikan sebagai perbandingan antara ekspektasi konsumen dengan kenyatan pelayanan 
yang diberikan. Pelayanan merupakan hal yang langsung dirasakan oleh konsumen. Hal positif dari hasil pengamatan dilapangan bahwa karyawan selalu menggunakan baju seragam dan terlihat bersih serta keramahan karyawan pada setiap konsumen menciptakan kepuasan bagi konsumen. Pengamatan ini sesuai dengan hasil dari pernyataan pada kuesioner bahwa kualitas pelayanan berpengaruh terhadap kepuasan dan loyalitas pelanggan

Menurut Kotler (2003), penilaian konsumen secara keseluruhan terhadap manfaat produk dengan didasarkan pada apa yang mereka terima dan apa yang mereka berikan. Setiap konsumen memiliki penilaian yang berbeda-beda terhadap suatu produk. Kesesuaian harapan konsumen terhadap apa yang diraih pada produk akan menciptakan suatu kepuasan. Hal ini sesuai dengan hasil penelitian ini, bahwa penilaian konsumen berpengaruh terhadap kepuasan dan loyalitas pelanggan. Berdasarkan variabel yang diukur pada penelitian ini yaitu food quality, price, service quality dan perceived value berpengaruh terhadap customer satisfaction dan food quality, price, service quality dan perceived value secara parsial terhadap customer loyality serta variabel customer satisfaction mampu memediasi pengaruh food quality, price, service quality dan perceived value secara parsial terhadap customer loyality. Hal ini terlihat bahwa faktor kepuasan dari pelanggan mampu menumbuhkan sikap loyal dari konsumen terhadap suatu produk.

\section{SIMPULAN}

Berdasarkan hasil dan pembahasan terbukti food quality, price, service quality dan perceived value memberikan pengaruh yang signifikan terhadap customer satisfaction, terbukti food quality, price, service quality dan perceived value memberikan pengaruh yang signifikan terhadap customer loyality, terbukti bahwa customer satisfaction mampu memediasi hubungan antara food quality, price, service quality dan perceived value terhadap customer loyality

\section{DAFTAR PUSTAKA}

Bishop, W. R., Jr. 1984. Competitive intelligence. Progressive Grocer, 63(3), 19-20.

Dutka, Alan, 2008. AMA Hand Book for Customer Satisfaction. NTC Business Book,. Lincolnwood, Illinois Eva Yohana \& Edwin J, 2017. Pengaruh Perceived Service Quality Terhadap Customer Loyality Dengan Customer Satisfaction Sebagai Variabel Intervening di Hotel Kartika Graha Malang. Jurnal Manajemen Pemasaran Vol.11 No.2.

Essinger, James \& Wylie, Helen. 2003. Customer loyalty: Devising successful strategies in food and drink.

Gerson, Richard F. 2004. Mengukur kepuasan pelanggan.PPM.Jakarta

Jacoby, J., Kyner, D.B. 1973, "Brand Loyalty vs. Repeat Purchasing Behavior", Journal of Marketing Research, Vol. 1, pp. 1-9.

Jang, S., \& Namkung, Y. 2009. Perceived quality, emotions, and behavioral intentions: Application of an extended Mehrabian-Russell model to restaurants. Journal of Business Research, 62, 451-460.

Jimmy Sugianto \& Sugiono S, 2013. Analisa Pengaruh Service Quality, Food Quality dan Price Terhadap Kepuasan Pelanggan Restoran Yung Ho Surabaya. Jurnal Manajemen Pemasaran Petra, Vol.1 No.2

Kevin Hariyanto, 2018. Analisa Pengaruh Service Quality, Food Quality dan Perceived Value Terhadap Customer Loyality Konsumen Restaurant Boncafe Manyar Kertoajo Surabaya dengan Customer Satisfaction Sebagai Variabel Intervening.

Kotler, Philip, 2003. Marketing Management. The Millenium Edition. Prentice-Hall International Inc. New Jersey.

Kotler dan Amstrong. 2004. Prinsip-prinsip Marketing, Edisi Ketujuh, Penerbit Salemba Empat, Jakarta.

Lai, T.L. 2004, "Service Quality and Perceived Value's Impact on Satisfaction, Intention and Usage of Short Message Service (SMS)," Information System Frontiers, Vol. 6, No. 4, pp. 353-368.

Parasuraman, A., Zeithaml, V.A. and Berry, L.L. 1985, "A conceptual model of service quality and its implication", Journal of Marketing, Vol. 49, Fall, pp. 41-50.

Van Iwaarden, J., van der Wiele, T., Ball, L., and Millen, R. 2003, "Applying SERVQUAL to web sites: An exploratory study", International Journal of Quality \& Reliability Management, Vol.20, No.8, pp. 919-935. 
Yi, Y. (1990), “A critical review of consumer satisfaction”, in Zeithaml, V. (Ed.), Review of Marketing, 1990 ,

Zeithaml, V.A. 1988, "Consumer perceptions of price, quality and value: a means and model and synthesis of evidence", Journal of Marketing, Vol. 52 No. 3, pp. 2-22.

Zeithaml, V. A., Berry, L.L. \& Parasuraman, A. 1996. The behavioural consequences of service quality. Journal of Marketing Management, 60(No. April), 31-46. 